\title{
Working with groups using groupware: electronic problem structuring and project management support for face to face and dispersed organisational groups
}

\author{
F. Ackermann \\ Department of Management Science, \\ University of Strathclyde, 40 George Street, Glasgow \\ Tel +44 141552 4400, Fax +44141 5526686 \\ EmailFran@mansci.strath.ac.uk
}

\begin{abstract}
This paper uses experiences gained from working with both senior and middle managers in organisations to describe a number of 'observations' identified concerning the impact technology has upon groups using Groupware in a face to face environment. These observations along with two case studies describing different instances of dispersed group working (one focusing on electronic problem structuring, the other project management support) are then considered alongside the impact dispersed working has on facilitating groups using Groupware. Both the observations and the facilitation discussion focusing on providing facilitation to dispersed groups are aimed at providing researchers and users with insights into some of the potential difficulties experienced when implementing groupware systems.
\end{abstract}

\section{Keywords}

Groupware, facilitation, problem structuring, project management, dispersed group working, face to face group working

\section{INTRODUCTION}

For a large number of people the question "what is Groupware?" immediately comes to mind when either confronted with the numerous articles (Byte 1993; PC Week 1994) or books (Johansen, 1988; Lloyd, 1994; Coleman and Khanna, 1995, ) written on the subject. One definition given by 
Watson (1994) states that groupware is "about people and processes first; technology and systems second" whereas Coleman (1995) asserts that Groupware " impacts the way people communicate with each other" and Opper and Fersko-Weiss (1992) note that groupware "must in some way facilitate and promote group interaction". All three of these definitions focus on the issue of groups communicating and working together placing the role technology plays at a lower level.

One means of distinguishing groupware from other Information Systems is that groupware allows groups to work at anytime and in anyplace. As such group members are able to contribute to discussions and take responsibility for the implementation of actions regardless of their location, and work schedules - an attractive proposition to organisations working in different cities or countries looking to increase their effectiveness. For the majority of groupware packages, the concepts behind them are not new, Engelbart in the 1960 and 70s (Engelbart 1963; Engelbart et al 1973) suggested the idea of computer based networks for communication. However with the availability of fast, inexpensive and reliable networks (including ISDN and Internet links) within and between organisations the idea of electronic communication and working has become a reality for both business and business education (Alavi et al 1995).

A number of Groupware systems have already been developed to support group working at various levels and on different tasks. One of the most well known is Lotus Notes which, using an E-mail and text based format, provides a valuable means of communication for group members working together. However, while Lotus Notes and others help with communicating on structured, coordinated and well understood tasks, they are not as effective in supporting groups working on messy, complex, unstructured problems. One reason for this is that these systems structure information in a predominantly linear style whereas people, when working on complex problems, think beyond simple sequential text. N-dimensional structures which encourage the "properties of the whole" as well as the detail to emerge, provide a powerful basis for the sharing of ideas and expertise. Therefore, in considering the adoption and usage of a groupware system, it is worth ensuring that an appropriate system is adopted. Briggs and Nunamaker (1995) provide a useful framework for determining the different levels of information technology support.

This paper commences with a brief exploration of the background to Group Support Systems leading into a review of the impact technology and computer support has had on face to face working with Groupware. This review, it is asserted, is necessary as many of these impacts are considerably amplified when working in a dispersed environment and others give rise to potential questions and dilemmas. Using the findings of the review and observations from two case studies, the paper then moves onto investigating the impact dispersed working has on facilitating groups using Groupware as well as other opportunities to be had, before concluding with a reflection on the current state of understanding and suggesting further research angles. This focus on facilitation is due to the role of facilitator being seen as critical to the support of groups (Bostrom et al, 1993; Ackermann, 1996; McGoff and Ambrose, 1991), particularly those groups working on messy, complex and unstructured problems.

\section{BACKGROUND}

It is worth considering, however, what the underlying effects are of these groupware packages and their attendant information technology infrastructure. One question worth addressing is "what does this introduction of technology do to group working and dynamics?" Considerable research has been undertaken into the use of Group Decision Support Systems(GDSS)/Group Support Systems (GSS) - systems which in the main have relied on the same time/same place mode of working 
(Johansen 1988), i.e. face to face. It is notable from the findings that they are by no means conclusive in their verdict. Dennis and Gallupe, (1993) in a review of the history of GSS note "the results of early experiments can be summed up in one word: mixed. Some experiments suggested that GSS improved decision quality whilst others showed no effect or worse decision quality for groups using a GSS". According to Dennis and Gallupe, later field studies showed more positive findings with possible explanations being a) the size of group(increased), b) type of task (real and complex) and c) the inclusion of a facilitator. Nevertheless, it becomes obvious - we are still learning and will require more experiments, field studies etc before we can accurately predict and design such systems.

Groups working together are a complex aggregate of personalities, politics and power issues, content and substance. As such the systems employed need to be able to deal with all of these aspects rather than focus on one or two to the detriment of others. Laboratory studies offer valuable insights into individual components or sets of components but by their nature do not address the holistic superstructure - often a critical element. Field studies (McGrath 1984) however allow "testing" of such systems but are subject to criticisms (rightly so) of single case/uniqueness and subjectivity - although it is this author's contention that even lab studies suffer from subjectivity and designer bias.

\section{OBSERVATIONS OF THE IMPACT TECHNOLOGY AND COMPUTER SUPPORT HAS HAD ON GROUP WORKING}

So what have we learnt from our examinations of groups using such systems? What may be some of the impacts of technology to a group's decision making process? If we are to seriously consider extending computer support to dispersed group members, it stands to reason that we review how technology affects groups working in the same time/same place mode (Johansen 1988).

The following observations are gained from working with numerous organisational groups using the SODA/COPE multi-user system (Ackermann and Eden 1995a and b). The current software is designed to allow structuring and synthesis of the reasoning of many people, in a manner that can, through analysis, reveal important properties of combined wisdom. The process, provides significant productivity gains, better quality solutions, significantly higher levels of ownership of agreements made, and importantly group and organisational learning. Whilst the IT context has been primarily that of a single software user - the facilitator/analyst for the group, two years ago this single user group decision support was extended to enable multiple participants/ group members to interact with the software thus capitalising on the additional benefits of anonymity, fast data entry, and increased control over the expression of ideas/assumptions/assertions.

To provide group members with this interaction or 'direct entry' into the model, the software was extended to run on a network of PC's with each participant within the group being able to contribute, at the same time, to the problem structuring, evaluating and project management/ monitoring effort. This was achieved through "electronic brainstorming and linking", "electronic voting" in relation to desired and "no-go" options and "electronic rating" to determine either leverage (level of impact upon a particular variable) or progress. Observations of groups using this direct entry facility have shown that group productivity and participation is, on the whole increased.

This facility currently allows groups to work in the same place at the same time, building on rich communication protocols (non verbals). This mode of working can be instigated at various points during the collaboration. For example, to capture ideas, explore and negotiate a way forward, learn more about one another's roles and skills, and finally provide an organisational memory. This may 
be the first step in a meeting, allowing members to become familiar with one another and the technology. As such the multi-user allows;

- ideas to be entered directly into the system but in a graphical manner rather than linear. The relationships (linkages) between ideas can also be entered.

- voting on preferences where the original context is preserved, multiple criteria can be considered, and the results either hidden or displayed to the groups depending on the requirements (See figure 1 for the results of a voting session)

- rating to determine leverage or performance/ bench marking (used predominantly for evaluation of progress) (See figure 2 for a participant's screen when rating)

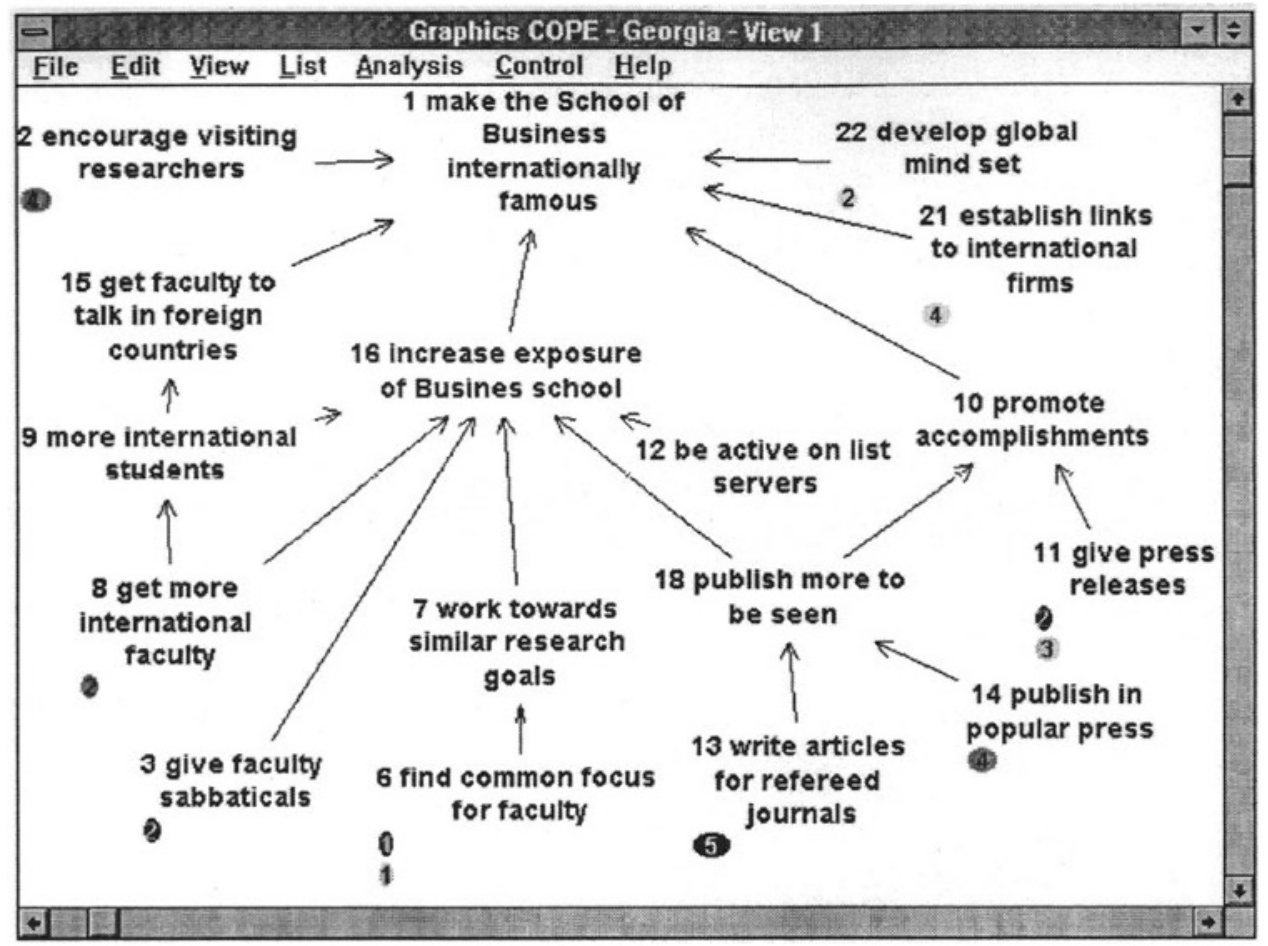

Figure 1 Results of voting exercise. 


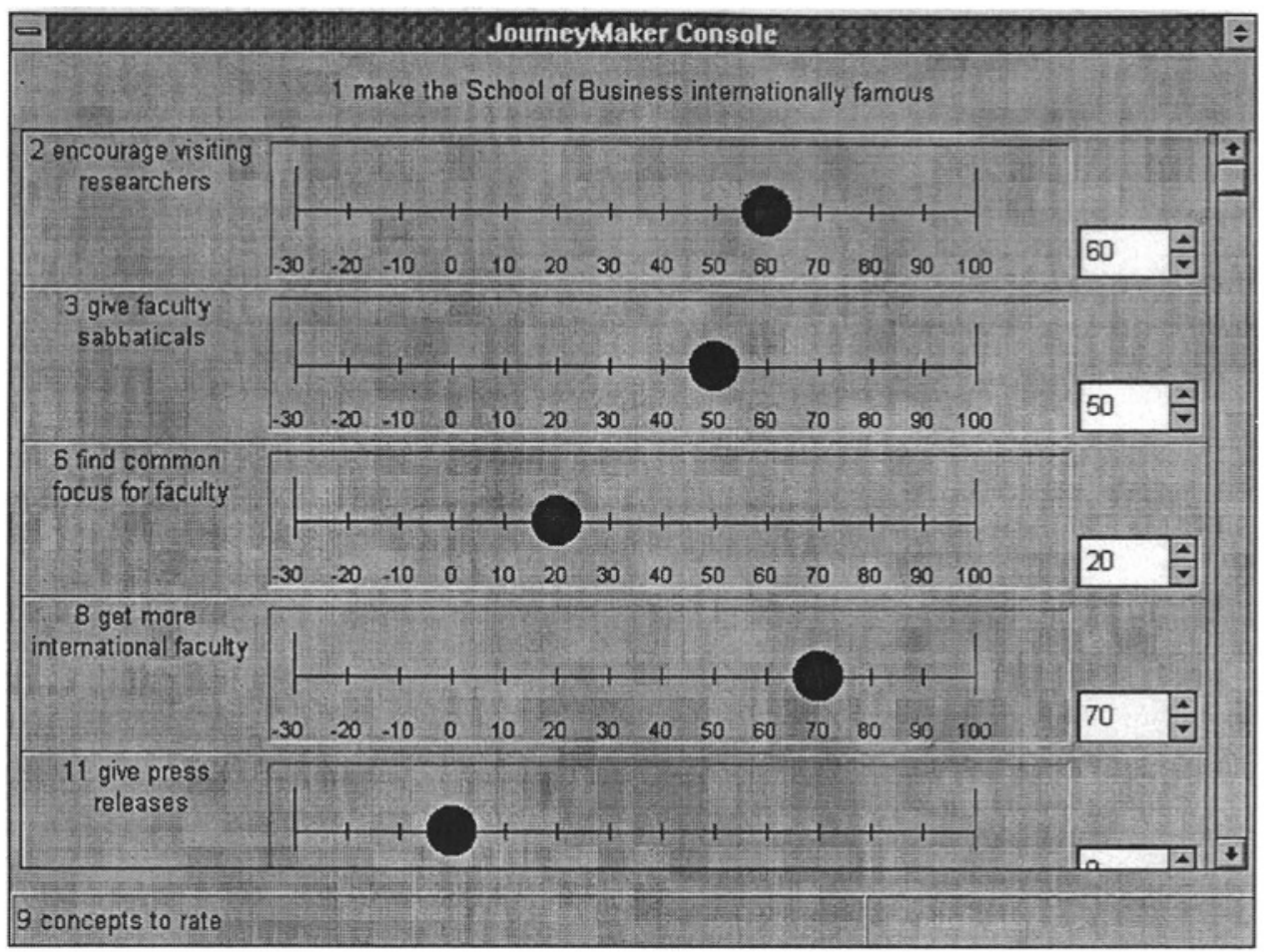

Figure 2 Example of the rating system

Along with

- the ability to switch between user entry and facilitator control over the model's contents. This facility is powerful as it allows the group members to develop a shared understanding of the content through moving between divergence (direct entry) and convergence (facilitator controlled)

- a monitoring system to detect generation, voting and rating patterns (see figure 3 below)

The observations were:

\subsection{Dealing with personality or status issues}

Dominant members (usually senior officers) often felt hobbled by the process of equality as they missed their ability to sway people or persuade their colleagues. Whilst this need to control the meeting may not be conducive towards increasing the creativity of group members or their ownership of the outcomes, it does raise issues relating to the ongoing nature of the group, ie can it continue to work together (a requirement of GDSSs according to Huber 1984) as well as the political feasibility of the outcomes (Eden 1991). If these, often powerful, people reject the process, 
it is going to be more difficult for others to support the outcome, thus diminishing the chances of implementation.

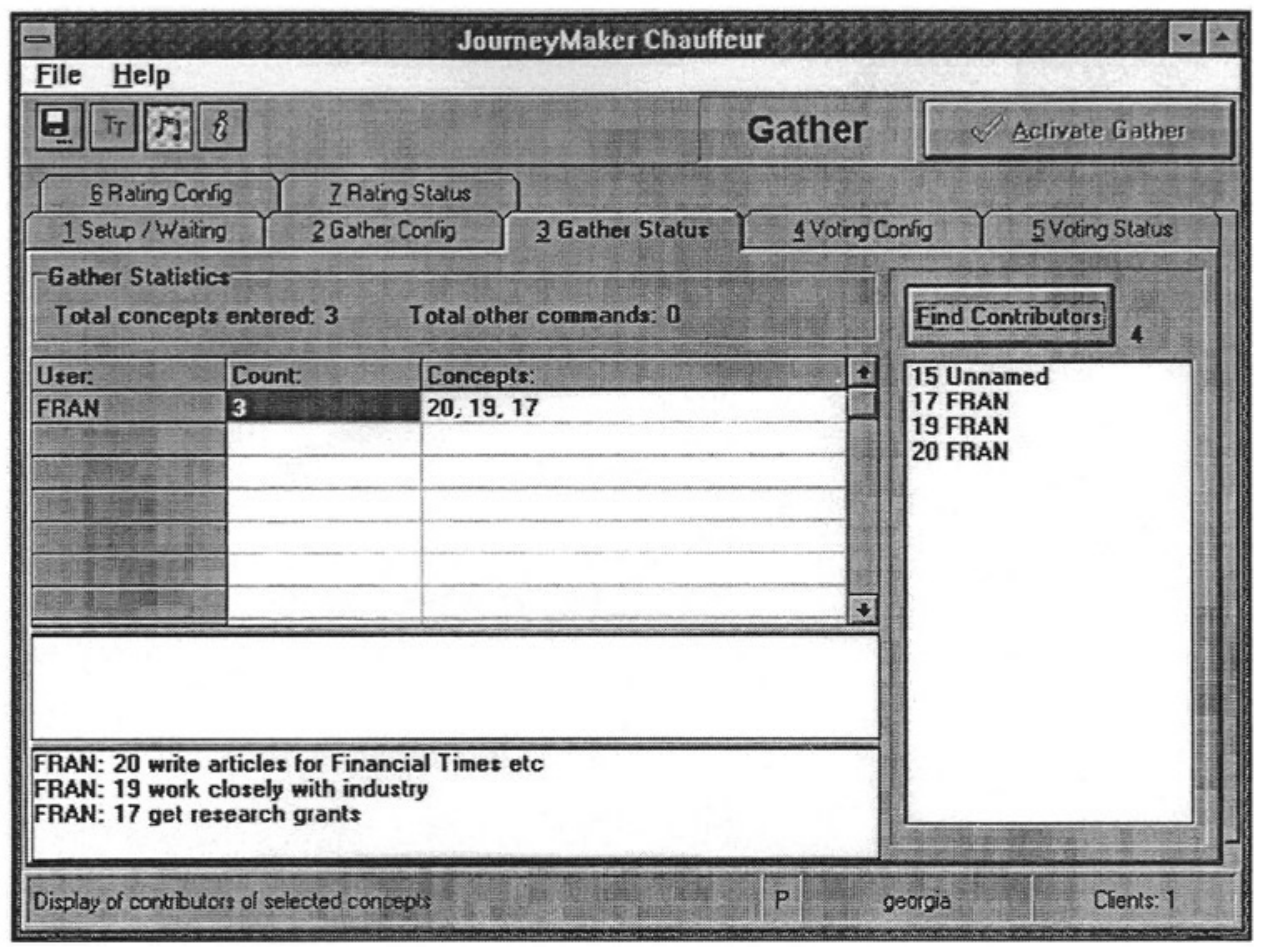

Figure 3 Example of the monitoring facility showing contribution levels etc.

This difficulty with equality is also evident when discussing the meetings with the 'client'. Organisations on the whole are not cooperatives, and to state implicitly or not that all members have an equal say in the decision, results in clients fecling uncomfortable if not threatened (Ackermann 1991; Ackermann and Eden 1995). Informing the clicnt that through the monitoring system (figure 3 ) it is possible to determine the generating, rating or voting patterns (for example have a largc number of people placed one vole on an issue or one person placed a large number of votes, or when gathering ideas has one person contributed lots of ideas or are they well spread). This ability, easily managed when working with manual systems as it is possible to observe the patiems, may go some way to reassuring clients who rely on the facilitator to ensure that the outcomes are those they will act upon, i.c. politically feasible. Whilst dealing with dominant or status issues is not necessarily a tcchnology problem it is seen to be more pervasive when using technology and steps taken to resolve it.

Alongside issues concerning the management of dominant or powerful members, it has been noted that 'quieter' members do not necessarily contribute more with tcchnology - nor for that matter does direct entry lead to quality ideas. In one case when working with a management team it was 
observed that a number of them entered very few ideas into the system. When gently questioned about this (by a colleague inside of the organisation) a number of them commented that in areas where they did not have direct experience or in depth knowledge they felt more comfortable remaining 'silent' and learning from their colleagues (Yeates, 1996). However they did appreciate that this 'silence' was not obvious to the group.

\subsection{Mixing manual, single user and multi user modes of working}

Having the ability to use a variety of support systems rather than just direct entry was seen to have the edge over just using multi-user/direct entry. This was partly to the variety providing a sense of mental refreshment. Looking at the screen all day was noted to be tiring particularly if the room being worked in had to be darkened to allow the projection device to work properly. Whilst it is acknowledged that projection devices through increases in resolution and power now perform better in daylight conditions, this requirement for mental refreshment continues to be an issue particularly if the meetings last one or two days.

Another benefit from having the different modes of working is that systems that support one task well may not be effective in supporting a different task. For example, the ability to allow group members to directly enter their ideas into the system provides the group with anonymity and the benefit of fast entry of ideas "talking simultaneously" (Nunamaker et al, 1988). However, once this initial generation has been completed, moving to the single user mode (facilitator driven) allows the group to begin to discuss the ideas that have emerged, and so begin to reach a common understanding about the issue/problem and how ideas, assumptions etc relate to one another (Ackermann and Eden 1995b). Relying on the facilitator to manage the system also frees up the group members, allowing them to concentrate on the task at hand, and avoiding them from having to learn how to operate the system and adhere to the rules (Ackermann 1996).

\subsection{Avoiding being reliant on technology}

Whilst great improvements have been made, both to the software and hardware available, it is never absolutely reliable. Through having a manual or single user backup an alternative is available should it become necessary - as well as providing the benefits listed above. In those circumstances where the system suddenly ceased to work (sometimes through no fault of the system, e.g. power failures) it was noted that the ongoing discussion was interrupted, often fatally, that the group members enthusiasm was diminished resulting in a sense of demotivation and that sometimes all the positive benefits of working electronically were wiped out.

However, working to avoid being reliant on technology may place extra effort on the facilitator. Not only does he or she have to be familiar with the direct entry system, but also with the manual or single user modes of working. Whilst this may not be a problem to a skilled facilitator who is used to working with different techniques, where the facilitator is the leader of the group who has only learned to use the direct entry supported system, this may result in either the meeting being postponed or even the system being rejected. It may be that where the GSS being used replicates existing and well known manual techniques eg listing ideas and categorizing them (eg Group Systems 1988) this transition between modes is easy, however, where the system is underpinned by a new methodology, for example SODA or Decision Conferencing (Quinn et al, 1985), then the transition is more complex. 


\subsection{Using portable rather than desk top machines}

Through working with a portable network, not only can the system be taken to the group's preferred location but also the above observation of moving between different modes of working is supported. Portables, by their very nature are easy to pick up and put down, and the system can easily be tailored to the number of group members rather than working in a room too large or too small. Furthermore, due to their size they avoid any visual clues from being blocked. However, they do have disadvantages in that there is a real danger of having the network connections terminated through cables being uncoupled from the computer and the number of machines available being dictated by the network setup.

\subsection{Working with groups familiar with the process compared with those new to the support system}

The group's familiarity with process was seen to have a significant effect on the way that the GDSS/GSS was introduced. Groups unfamiliar with technology in general (particularly the case with one organisation where over $60 \%$ were computer illiterate) experienced a sense of apprehension and wariness. This situation may be compounded when using portable systems as the 'spaghetti' like nature of the cabling raises group member anxiety. Not only are members faced with operating the computer but also with a new way of working, one that is unfamiliar to them. Where the groups begin working with a manual system, becoming acquainted with the particular way of capturing and structuring information, and then move to the technology the transition becomes more natural and less obtrusive. Even so, reassuring those members who are concerned that they might 'crash' the system is still important.

Once group members had become more expert with the system a different issue emerged - how to manage groups where a large number were experienced with the system but one or two required further attention. Those members comfortable with the direct entry mode and computers in general were impatient to start working whereas those new to the process were faced not only with a new way of working but also a set of colleagues eager to get started. Reminding these seasoned group members that they too had experienced the same concerns helped in managing the group dynamics.

\section{$4 \quad$ USING GROUPWARE WITH DISPERSED GROUPS}

To support groups working with more qualitative and subjective issues, for example strategy development and implementation, and noting the above observations of face to face work, a research project has been set up to develop a unique, and powerful means for enabling group members who may be in different locations to work effectively. One focus is to develop the methodology to enable group members to make decisions based upon ideas and comments entered into a model at different times and from different locations using an "electronic conversation" or "electronic problem structuring" process. Not only would this ensure that when the group members got together to finally decide on a course of action, the meeting was as effective and efficient as possible but also allow members to contribute at more conducive times rather than being forced to be creative at a set times (Case Study 1). The second focus concentrated on using an existing model (perhaps developed during a face to face series of meetings) for project management or reviewing progress (Case study 2). 
In both different place/different time situations, the software's ability to capture both ideas and their relationships along with its extensive analytical facilities provided the means for examining the holistic nature of the issue rather than just the individual parts. This allowed group members to begin to explore and play with the model (Eden 1993) thus increasing their understanding of the issues and associated ramifications. However, in order to begin to explore electronic problem structuring conversations and project management a number of changes had to be made to the software. These were:

- Simultaneous access to the system. This was to allow multiple group members to be able to conduct an electronic 'problem structuring conversation' discussing issues and options or to discuss the operationalisation of agreed actions. Through using network protocols to 'lock' ideas and relationships, thus ensuring that several users do not manipulate the same part of the model at the same time, group members would be able to view the same material and work together. Not only would this ensure that the meeting was as effective and efficient as possible but would also allow members to contribute at appropriate times rather than being forced to be creative at a set time.

- Support for sharing ideas and data between group members. By using a bulletin board to alert members to specific issues of interest, and creating shared/global views (argumentation supporting a particular point of view) group members can begin to share ideas around a specific topic. This facility also aids project management as it allows group members to jointly develop the system of ideas, and consequently take ownership of the outcomes discussed. In addition, they can implement these outcomes with reference to the agreed direction. Changes made can then be entered into the system with those responsible being able to track and monitor progress.

\subsection{Case study 1}

The particular organisation involved a number of senior executives engaged in a complex strategy development issue. All of the executives were extremely busy people, often spending more of their time outside of the office than at their desk. As such finding time to get together was problematic and when they did meet they wanted to ensure that the time was spent as effectively as possible. Using the dispersed mode of working over a period of two weeks, the executives used the system to discuss the complex issue, spending short bursts of time entering ideas as they occurred to them, browsing through the material suggested by their colleagues and adding new comments prompted by other's material and raising questions. The structuring element of the system allowed the material to be managed effectively through showing how options could have both positive and negative effects, displaying feedback loops and demonstrating key or 'busy' ideas. In some instances the time actually spent entering ideas and exploring the model's contents only lasted 10-15 minutes - fitted in between other meetings when ideas or issues germane to the topic occurred to them.

Following this asynchronous discussion, a face to face meeting was held using the resultant model. Within 30 minutes the group had managed to resolve the issue and agree upon a set of actions. The dispersed mode of discussion had allowed them to 'speak', 'listen', 'comment' and reflect in their own time so that when they came to the meeting, they were already familiar with the material and its nuances. Consequently the process had maximised the efficiency of their time when getting together as a group (Bedgood, 1993). 


\subsection{Case study 2}

The second organisation used the system in reverse. Through working together in the face to face mode the senior managers had developed a system of ideas (the model) reflecting the strategic direction that they hoped to take along with the associated actions necessary to achieve the direction. They had involved a large number of staff members in the process (to gain ownership and understanding) and had even incorporated key clients (to ensure that the resultant strategy was not in conflict with the client's aims and aspirations). Once the strategy model had been agreed upon by the management team, the individual team members agreed to take responsibility for particular issues and associated actions. To support the implementation process, the model containing all of the actions and their rationale was placed on the network for easy access. As the actions were started, substantially progressed or completed they were categorised accordingly - the categories being in the form of colours denoting progress (Ackermann et al 1992). In addition, to support the implementation further, job descriptions and roles were changed to match the strategic direction moving away from a traditional structure to one more suited to the strategic direction and future of the organisation.

Through enabling the management team access to the model and facilities to record progress, the Chief Executive was able to track progress on all the actions, promulgate successes and nudge those falling behind. When alterations were necessary due to changes in either the internal or external environment, they could be made in the light of the model/strategic direction as a whole. By sharing views and alerting one another to changes through an electronic message facility, new actions could be introduced that not only supported the area in question but also had benefits for other parts of the organisation - thus acting both corporately and synergistically. Members could share their views and post electronic messages (Miller and Ackermann, 1994).

\section{PROVIDING FACILITATION TO DISPERSED GROUPS WHEN WORKING ANYTIME/ANYWHERE}

One of the issues that has emerged from these two case studies, the observations of same place same time groups and reading the literature is the importance of facilitation. It has been noticed that when working on predominantly structured tasks with clearly defined roles groups are reasonably able to manage themselves. However, when the issue or problem is more unstructured, complex and has political ramifications for the group members facilitator assistance is often needed and sought. This belief that the inclusion of facilitators is important to the success of GDSSs has been supported in reports regarding face-to-face work, for example McGoff and Ambrose's statement that "experience continues to confirm that the quality of the group session is predominantly dependent on the facilitator" (1991) and when a facilitator is present to "manage both process and the content" (Phillips and Phillips 1990; Eden 1990; McGoff and Ambrose 1991). Translating this facilitation support to dispersed working however, raises a number of issues hitherto unexplored as the group working becomes fragmented, sporadic and less coordinated, and as such the question arises as to which or whether many of the skills/ procedures adopted by face to face facilitators can be utilised.

Some of the guidelines provided by researchers discussing facilitation, for example, providing clear objectives and an agenda for the process, agreeing upon who should be involved, prompting participants to perceive themselves to be equal for the event can probably be accepted without much 
hesitation. For these guidelines a slightly different packaging might be all that is needed. However from observations gained from the two cases studies noted above and conversations with other groupware researchers there appear to be other significant facilitation issues that need to be addressed, some of which include;

* developing methods for helping groups work with the large, complex structures they develop,

* keeping the model (or discussion) up to date and relevant,

* ensuring that related areas are adequately linked together rather than disconnected,

* finding ways to prompt members, keep the energy flowing and test assumptions, and

* building in some form of model review and maintenance.

Whilst some of these new facilitation issues are already being examined through reviewing current groupware projects, many of these are reactive rather than proactive - a not surprising finding given the newness of the field. Nevertheless, further research into group dynamics, facilitation methods and the impact distributed working will have on groups will require considerable attention and carefully conceived research design both in laboratories and in field studies. Furthermore, as these systems do become more prevalent and are used by groups working globally further complications in the light of facilitating multi-cultural groups will arise linking the research into cultural collaboration with group working and electronic support.

One avenue to consider when investigating how to support groups using groupware is through disaggregating the skills and techniques used by a facilitator. It has been argued that a number of the tasks undertaken by a facilitator could be automated (for example linking tools eg from brainstorming to voting) and that tasks such as prompting for the relationships between ideas, requests for elaboration, and reminders to contribute could be introduced into the groupware system. Another means of circumventing the difficulty is to design carefully tailored 'help' packages where the group members themselves become more self reliant and work to manage the group's effort. Both of these options however, tend to focus on tasks that are to some extent structured and where the political ramifications are small.

Nevertheless, in many circumstances the facilitator is brought in to a) provide a different perspective, or content expertise to the group, b) as a means of having a relatively unbiased person guiding the meeting, or $\mathrm{c}$ ) harnessing a specialised set of skills. All three of these rationalisations defy automation or training. Firstly an outside facilitator not only brings new perspectives but can force a group to question their 'world taken for granted', the established practices (Ackermann 1996), prompting a fresh look at the issue or problem in question. Secondly, when using sophisticated modelling systems in order to structure the information particular coding rules apply. Ensuring that group members conform to information capture guidelines, not only to ensure the consistency of 'coding' data, but also to enable the various forms of analysis to be used as effectively and accurately as conceived, requires additional energy and commitment on the part of the members. The final point, that of bringing a relatively unbiased perspective is virtually unresolvable. 


\section{OTHER OPPORTUNITIES}

For much of the groupware literature, readers could be forgiven for assuming that on the whole Groupware was used for either face to face meetings (Same Time, Same Place) or dispersed asynchronous meetings (Different Times/Different Place). However the two intermediary quadrants also provide powerful incentives. If groupware systems can be developed to support group working in all four of the quadrants, thus freeing up groups to work when and how they like then groupware will become a powerful system. One of the commonly asserted characteristics of Groupware is that the system must be 'seamless' (Malone 1992). This seamlessness may be the transfer of information between the different working modes as evidenced in the case studies, or the development of easy and intuitive to use interfaces (adopting existing ways of working and tapping well established routines). Given industry's often shy behaviour around information technology introduction, it is probably worth addressing both of these forms of seamlessness so as to quickly buy people into the benefits without any of the difficulties often associated with software.

Taking this request to address all four quadrants seriously, it is worth considering some of the instances where it can be conceived that the COPE groupware system may be applied to support the other two quadrants:

\section{Different Time/Same Place}

a) the organisational memory (the resultant model developed by the group) can be continually monitored for progress (either by group members or the Managing Director) and progress reports provided for departments, organisations, steering groups etc.

b) new members joining the organisation can quickly and easily determine the strategic direction, identify how the different parts of the company work together, explore areas relating to their sphere of influence and therefore be able to contribute more effectively

Same Time/Different Place

a) members in different locations will be able to discuss possible alternatives and coresponsibilities while viewing and expanding a joint representation of the issue. This development will help increase understanding through providing context whilst also ensuring that any alternations are made within the context of the overall direction of the collaboration. The model may be used as a means of exploring the issues, structuring the dialogue, visualising the different ramifications whilst maintaining communication through a standard phone conversation. In addition the resultant image provides a form of artefact - a transitional object - that the two group members can refer to at any time.

b) any new actions/ideas can be assessed to ensure that they support rather than conflict with existing work.

\section{$7 \quad$ CONCLUSIONS}

If groupware is to reach its full potential then many of the above issues do require investigation. One of the ways we can increase the chances of groupware systems being used by dispersed groups is to reflect upon the observations noted from face to face groups and try to determine how they relate and impact on dispersed working. The first observation, dealing with personality or status issues, appears to continue to be relevant with senior or dominant members either avoiding using groupware systems or struggling with more apparently equal modes of working. In an environment 
where non verbals are not available through group members being in different locations, it is easy to conceive of group members expecting an even greater degree of equality and freedom. Thus it becomes more important to make clear the distinction between being able to influence the direction and having a clear decision making prerogative.

Being able to mix manual, single user and multi-user modes of working to stimulate and refresh members does fail with dispersed working. However, to some extent it becomes replaced with the freedom to contribute when conducive. One of the important factors present in both of the case studies was the fact that the group members were familiar with the method of working and had used the software, albeit in single user mode, already. This familiarity appears to be a key factor in the adoption of groupware systems (as reflected in the observations) with novice groups potentially balking at having to learn new methods, software systems and ways of working together.

The two observations focused on technology have radically different ramifications. If groups are going to work in a dispersed mode using groupware then inevitably they are going to be reliant on technology and so the need for robust software becomes imperative. However whilst reliance on technology may well be seen as a potential danger, it may also provide some benefits. For example, group members using portable computers are able not only to work with them as 'desk top' machines (by connecting them to an external monitor, keyboard and office network) and therefore contribute to dispersed, asynchronous work but also use them for working in a same time/same place environment. This 'portability' may well contribute towards making the groupware process more seamless as moving between modes of working (any time/any place) becomes effortless.

As mentioned earlier the issue of group facilitation also requires attention as groups working at different times and places demand additional support. One particular demand is the increased need for monitoring the group's progress - during the discussion, evaluation and implementation stages. Models for automating facilitation must be investigated, but these impersonal aids often result in as many disadvantages as advantages. Automation often results in constraints as group members have to work within the parameters set by the automation. As such exploration in the field of artificial intelligence may provide some clues as to how a system can be developed that 'grows' with the user and can be tailored to meet the different styles of group members - a common requirement for Decision Support Systems (Sprague and Carlson, 1982). Teaching group members how to be self facilitators also raises concerns as for many of the potential users finding the time and energy is a problem - as is a concern about whether they will recoup the effort put into learning how to use the systems in productivity and effectiveness increases.

Finally, the question of whether organisations and their staff actually want to work remotely must be examined. For many of these systems to work successfully a change in organisational working practice must take place. It will become necessary to develop a means where a) collaborative working is accepted, b) sharing of information is seen as acceptable and necessary and c) decision makers consider the strategic development of the collaborative project as paramount. For many organisations this openness is both new and radical and as such avoided. Nevertheless there is a growing belief that sharing is necessary, that in order for teams to become empowered and collaborative and through the introduction of techniques like Business Process Reengineering (Hammer and Champy 1993) systems such as groupware offer rich opportunities.

\section{REFERENCES}

Ackermann, F. (1991) 'Consideration of a Specific Group Decision Support Methodology in the light of the Group Decision Support Systems Literature' Phd thesis, unpublished $\mathrm{PhD}$ thesis 
Ackermann, F. (1996) 'Participants Perceptions on the Role of Facilitators using Group Decision Support Systems', Group Decision and Negotiation, 5 93-112

Ackermann, F. and Eden, C. (1995a) 'Visual Interactive Modelling: using multiple workstations for problem solving and action programming' Presented to TIMS/ORSA conference, Los Angeles, April.

Ackermann, F and Eden, C. (1995b) Contrasting GDSS's and GSS's in the context of strategic change - implications for facilitation' proceedings of the Inaugural America Conference on Information Systems, Pittsburgh, August

Ackermann, F. and Eden, C. (1994) 'Issues in Computer and Non-Computer Supported GDSSs' International Journal of Decision Support Systems, 12 pp 381-390

Ackermann, F., Cropper, S. and Eden, C. (1992) 'Moving between Groups and Individuals using a DSS' Journal of Decision Sciences pp 17-34

Alavi, M., Wheeler, B.C., and Valacich, J.S. (1995) 'Using IT to Reengineer Business Education: An Exploratory Investigation of Collaborative Telelearning', Management Information Systems Quarterly, 3 293-312

Bate, J.S. and Travell, N. (1995) Groupware: Business success with computer supported cooperative working. Alfred Waler, Henley on Thames.

Bedgood, D. (1993) 'An assessment of networked Graphics COPE as a groupware tool for Shell International' MSc in Operational Research thesis, Strathclyde University

Bostrom, B., Anson, R. and Clawson, V. (1993) 'Group Facilitation and Group Support Systems'. In L. Jessup and J. Valacich (eds) Group Support Systems: New Perspectives. Van Nostrand Reinhold, New York .

Briggs, R. and Nunamaker, J. (1995) 'Getting a grip on Groupware' in P. Lloyd (ed) Groupware in the 21st Century. Adamantine Press Ltd, London.

Byte (1988) In Depth Groupware, edited by J. Morill, 242-282

Coleman, C. and Khanna, R. (1995) Groupware; Technology and Applications. Prentice Hall, Engelwood Cliffs, NJ

Coleman, D. (1995) 'Groupware Technology and Applications; An Overview to groupware' in Groupware; Technology and Applications in C. Coleman and R. Khanna, (eds). Prentice Hall, Englewood Cliffs, NJ; - 38

Dennis, A and Gallupe, B. (1993) A History of Group Support Systems Empirical Research: Lessons Learned and Future Directions. In L. Jessup and J. Valacich (eds) Group Support Systems: New Perspectives. Van Nostrand Reinhold, New York .

Eden, C. (1989) 'Using cognitive mapping for strategic options development and analysis (SODA)'. In J. Rosenhead (ed) Rational Analysis for a Problematic World, Wiley, Chichester

Eden, C. and Ackermann, F. (1992) 'Strategy Development and Implementation - the role of a Group Decision Support System' in S. Kinney, B.Bostrom and R. Watson (eds) Computer Augmented Teamwork: A Guided Tour. Van Nostrand and Reinhold, New York.

Eden, C. (1993) 'From the Playpen to the Bombsite: The Changing Nature of Management Science,' Omega, in press

Eden, C. (1991). "A Framework for Thinking About Group Decision Support Systems (GDSS)", Group Decision and Negotiation, 1, 2, 199-218

Engelbert, D.C. (1963) 'A Conceptual Framework for the Augmentation of Man's Intellect'. In P.W. Howerton and D.C Weeks (eds) Vistas in Information Handling Vol 1, Spartan Books, Washington DC 1-29. 
Engelbart, D.C., Watson, R.W., and Norton, J. (1973) 'The Augmented Knowledge Workshop' in AFIS Conference Proceedings, Vol 42, National Computer Conference and Exposition, June 4-8, New York City. AFIPS Press

Hammer, M and Champy, J. (1993) Reengineering the Corporation: A Manifesto for Business Revolution. Nicholas Brealey Publishing, London.

Huber, G. (1984) 'Issues in the Design of Group Decision Support Systems', Management Information Systems Quarterly 8 195-204

Johansen, R. (1988) Groupware; Computer support for Business Teams. Free Press, New York

Lloyd, P. (1994). Groupware in the 21st Century; Computer Supported Co-operative Working toward the Millenium. Adamantine Press Ltd, London.

McGoff, C.J. and Ambrose, L. (1991) 'Empirical Information From the Field: A Practioners' View of Using GDSS in Business', in the Proceedings of the 24th Annual Hawaii International Conference on System Sciences, Vol 3, Society Press, Los Alamitos, CA 1991

McGrath, J. (1984) Groups: Interaction and Performance. Prentice Hall, Englewood Cliffs NJ.

Malone, T. (1992) Defining Groupware - The History and Functionality of Groupware from both Theoretical and Commercial Perspectives'. Network World - Groupware Today, September.

Miller, A. and Ackermann, F. (1994) 'Soft Focus Re-Engineering' Presented to the Strategic Planning Society/Operational Research Society conference on 'Recipes for Re-Engineering, London May

Nunamaker, J.F., Applegate, L.M. and Konsynski, B.R. (1988) 'Computer-aided Deliberation: Model Management and Group Decision Support, Journal of Management Information Systems, 35-19

PC Week (1991) Groupware; The Teamwork Approach, PC Week supplement, October 14 Vol 8 No 41

Phillips, L.D. and Phillips, M.C. (1990) 'On Facilitating Groups' Working Paper, Decision Analysis Unit, London. London School of Economics and Political Science

Quinn, R.E., Rohrbaugh, J. And McGrath, M.R (1985) Automated Decision Conferencing: How it works', Personnel, 62 pp 48-55

Sprague, R.H. and Carlson, E.D. (1982) Building Effective Decision Support Systems. Englewoord Cliffs, NJ: Prentice Hall

Yeates, D. (1996) 'Developing and Implementing a Strategic Direction for Govan Initiative Ltd using SODA' unpublished MBA these, Strathclyde Graduate Business School

\section{BIOGRAPHY}

Fran Ackermann is a lecturer in the Department of Management Science at Strathclyde University. Her main research interests are focused around the areas of Group Decision Support Systems, Strategy Development and Implementation and Facilitation. Within the GDSS field itself, specific research projects include exploring and enhancing the links between group and individual work, developing methods for group members to enable them to contribute to discussions operating in a 'different time/different place' paradigm, and investigating how to aid managers working with complex qualitative problems. She has written numerous papers on the subject and is President of the European Group Decision Support Working Group. Her research has involved supporting decision making groups on messy, complex problems and has included working with organisations such as Shell International, AMEC Process and Energy Ltd, and the National Health Service using a methodology developed by herself and others at Strathclyde - namely SODA. 